ISSN 1029-8940 (Print)

ISSN 2524-230X (Online)

УДК 598.2:574.589

https://doi.org/10.29235/1029-8940-2019-64-4-478-483

Поступила в редакцию 14.11.2018

Received 14.11.2018

\author{
А.С. Пышко \\ Научно-практический центр НАН Беларуси по биоресурсам, Минск, Республика Беларусь

\section{ФАКТОРЫ, ОПРЕДЕЛЯЮЩИЕ СОСТАВ ВОДНО-БОЛОТНЫХ ПТИЦ ПРИ РЕНАТУРАЛИЗАЦИИ ВЫРАБОТАННЫХ ТОРФЯНИКОВ}

\begin{abstract}
Аннотация. В работе приведены результаты исследований численности и пространственного распределения 17 видов водно-болотных птиц на территории торфоразработки «Докудовское» в Лидском районе Гродненской области в 2012-2018 гг. На основании анализа динамики популяционных показателей и изменений структуры местообитания выделены три основных фактора, воздействующих на сообщество птиц затопленного торфяника: гидрологический, биотопический и фактор беспокойства.

Ключевые слова: факторы, водно-болотные птицы, сукцессия, затопленный торфяник

Для цитирования: Пышко, А.С. Факторы, определяющие состав водно-болотных птиц при ренатурализации выработанных торфяников / А.С. Пышко // Вес. Нац. акад. навук Беларусі. Сер. біял. навук. - 2019. - Т. 64, № 4. C. 478-483. https://doi.org/10.29235/1029-8940-2019-64-4-478-483
\end{abstract}

\begin{abstract}
A.S. Pyshko
Scientific and Practical Center for Bioresources of the National Academy of Sciences of Belarus, Minsk, Republic of Belarus
\end{abstract}

\title{
FACTORS DETERMINING THE COMPOSITION OF THE WETLAND COMMUNITY AT RENATURALIZATION OF THE DEVELOPED PEATBOARDS
}

\begin{abstract}
The paper presents the results of studies of the number and spatial distribution of 17 species of waterbirds on the territory of the "Dokudovskoye" peat development in the Lida district of the Grodno region. in 2012-2018. Based on the analysis of the dynamics of population indicators and changes in the structure of the habitat, three main factors affecting the bird community of the flooded peatland were identified: hydrological, biotopic, and disturbance factors.

Keywords: factors, wetland birds, succession, flooded peatland

For citation: Pyshko A. S. Factors determining the composition of the wetland community at renaturalization of the developed peatboards. Vestsi Natsyyanal'nai akademii navuk Belarusi. Seryya biyalagichnych navuk = Proceedings of the National Academy of Sciences of Belarus. Biological series, 2019, vol. 64, no. 4, pp. 478-483 (in Russian). https://doi.org/10.29235/1029-8940-2019-64-4-478-483
\end{abstract}

Введение. С начала XXI в. на территории Беларуси проводятся работы по искусственному восстановлению гидрологического режима отработанных торфяников («Торфяники-1», «Торфяники-2», «Ветландс») [1]. По результатам проведенных мероприятий на данных участках формируются водные угодья, которые активно заселяются представителями водно-болотной авифауны, а продолжающиеся сукцессии растительных комплексов на восстановленных участках способствуют постоянным изменениям сообщества водно-болотных птиц. В связи с этим необходимы организация постоянного орнитологического мониторинга, накопление многолетних данных по качественному и количественному составу населения птиц, их биологии.

Цель иследования - установление механизмов, определяющих динамику фауны на территории торфоразработки «Докудовское», для совершенствования методов управления как нарушенными, так и естественными природными объектами и обеспечения охраны птиц и ценных местообитаний.

Материалы и методы исследования. Исследования проводили на территории торфоразработки «Докудовское», расположенной в восточной части Лидского района Гродненской области. В 2007 г. часть отработанного торфяника площадью 2,74 км² подверглась искусственной ренатурализации путем вторичного заболачивания. Для этого были построены дамба протяженно-

(C) Пышко А.C., 2019 
стью около 1 км и два гидрорегулирующих сооружения. В итоге образовался непересыхающий в течение года водоем со сформированным зеркалом, началось образование участков болотной и водной растительности [2].

Изучение сообщества водно-болотных птиц проводили в южной части затопленного участка торфоразработки вблизи автомагистрали М6 «Минск-Гродно» с 2012 по 2018 г. (за исключением 2013-2014 гг.). Площадь мониторингового участка составила 1,3 км².

В 2012 г. территория мониторингового участка представляла собой водоем, который был пересечен сетью каналов и межкарьерными бровками - выступающими участками суши вдоль каналов. Длина каналов варьировалась от 90 до 300 м, а расстояние между ними составляло 90-200 м. Глубина воды достигала 0,5-1,5 м, а в каналах -3 м. Сообщества надводной растительности на начальных стадиях были слабо сформированы, участки мелководий лишь местами поросли манником, крупными осоками, а также небольшими куртинами рогоза широколистного [2].

В 2015-2017 гг. вследствие прогрессирующего зарастания территории участка площадь открытой водной поверхности значительно сократилась [3]. Увеличилась площадь зарослей рогоза, а по северо-восточному периметру мониторинговой площадки сформировалась полоса тростников. Мелководные участки постепенно покрывались ивовым кустарником. Площадь межкарьерных бровок увеличилась, а рядом с ними начали образовываться сплавины. Сами бровки поросли ивняком и травянистой растительностью. Уровень воды по сравнению с 2012 г. несколько снизился [4].

В 2018 г. в результате увеличения территории участков надводной растительности площадь открытой водной поверхности сократилась - ее доля составляла 42 \% от общей площади исследуемой территории. Заметно снизился уровень воды (глубина ее не превышала 1 м), и только в каналах она достигала 2 м.

Полевые работы проводили преимущественно в конце апреля - середине мая, в период наиболее массового гнездования водно-болотных птиц. Характер пребывания на данной территории и учеты численности водно-болотных птиц оценивали с использованием стандартных орнитологических методик, таких как маршрутные учеты (пешие вдоль береговой линии или по межкарьерным бровкам), абсолютные учеты (с использованием надувной резиновой лодки), картирование обнаруженных гнезд и мест локализации отдельных гнездовых пар и колониальных поселений.

Факторы, которые могли стать причиной изменений в сообществе водно-болотных птиц на территории затопленного торфяника, оценивали путем сравнительного анализа численности, видового разнообразия и территориального распределения водно-болотных птиц с динамикой биотических характеристик территории мониторингового участка.

Результаты и их обсуждение. Всего за период исследований на территории мониторингового участка установлено обитание 17 видов водно-болотных птиц, относящихся к четырем отрядам: Поганкообазные (Podicipedidae), Гусеобразные (Anseriformes), Ржанкообразные (Charadriiformes) и Журавлеобразные (Gruiformes). Наиболее разнообразным был видовой состав гусеобразных 10 видов. Остальные три отряда птиц были представлены 1-4 видами.

Установлено, что общая численность водно-болотных птиц на мониторинговой площадке на протяжении всего периода исследований неуклонно снижалась. Так, в 2012 г. она составляла 2662 пары, а в 2018 г. - всего 64 пары (рис. 1).

Видовой состав орнитофауны мониторингого участка, в отличие от численности, не подвергался столь значительным изменениям. Так, в 2012 г. здесь было зарегистрировано 14 видов, в 2016-2017 гг. разнообразие птиц достигло максимума - 17 видов, а в 2018 г. резко понизилось до 12 видов (рис. 2).

Резкое снижение к 2018 г. общей численности водно-болотных птиц обусловлено в первую очередь исчезновением крупной колонии озерной чайки (Larus ridibundus). Данный вид являлся доминантным в 2012-2017 гг., составляя более $80 \%$ от общего числа учтенных пар. Резкое снижение численности озерной чайки в последнем сезоне обусловлено снижением привлекательности данного участка для размножения вида в результате прогрессирующей растительной сукцессии. У других представителей отряда ржанкообразных (речной (Sterna hirundo), черной (Chlidonias nigra) и белощекой крачек (Chlidonias hybrida)) также наблюдалась отрицательная динамика численности. 


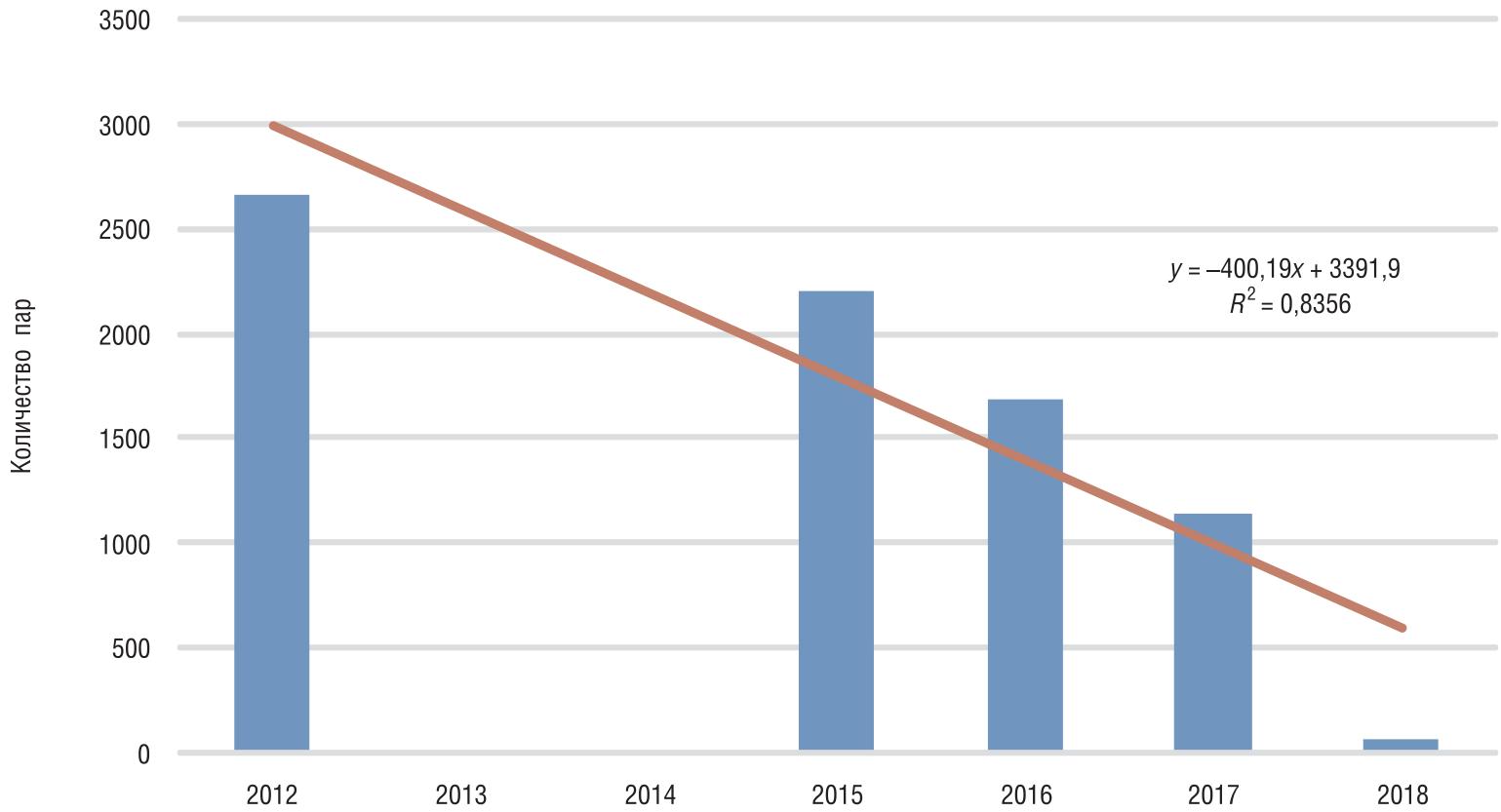

Рис. 1. Динамика численности водно-болотных птиц на мониторинговой площадке

Fig. 1. Dynamics of waterfowl numbers on the monitoring plot

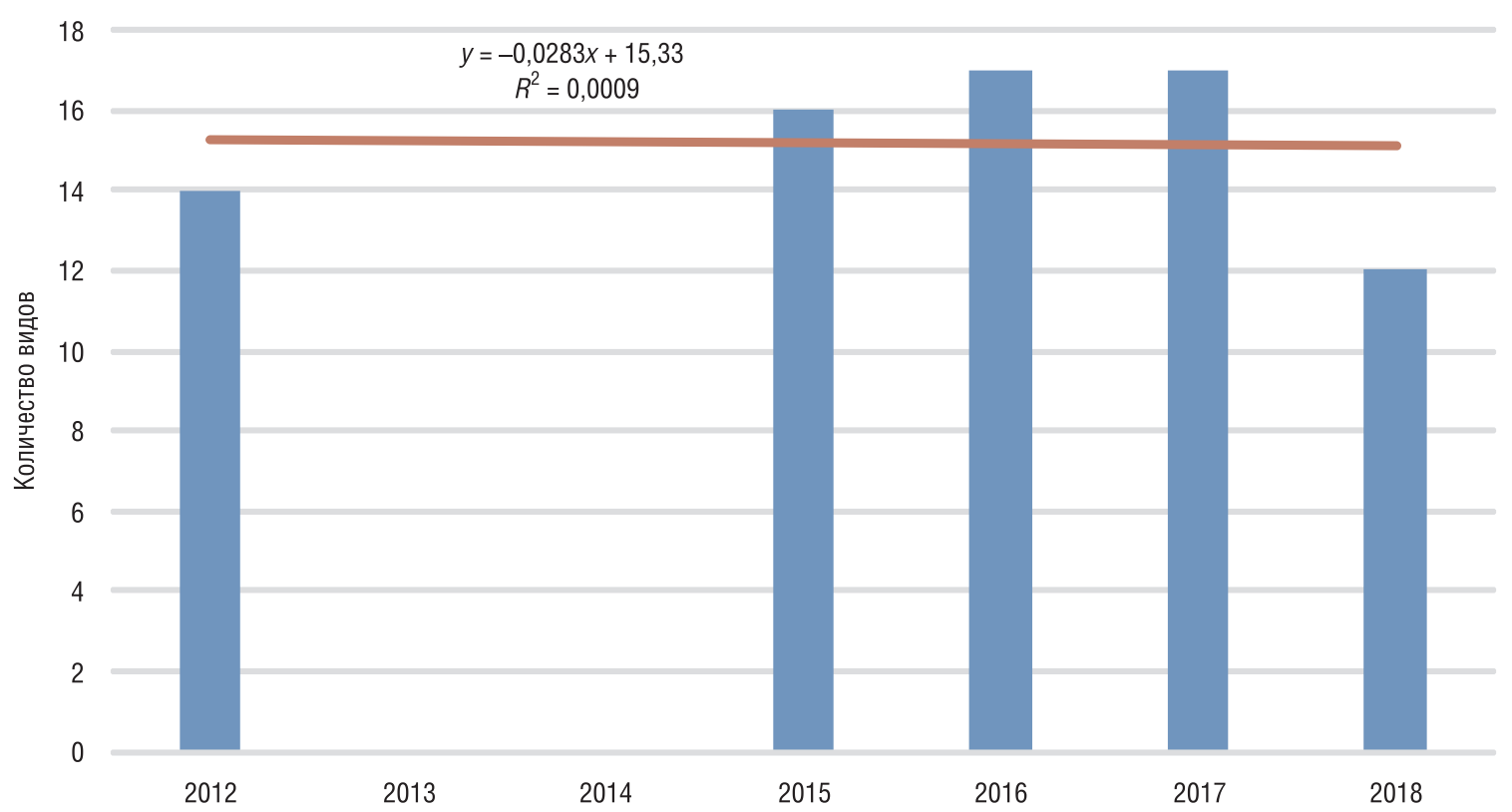

Рис. 2. Динамика видового разнообразия водно-болотных птиц на мониторинговой площадке

Fig. 2. Dynamics of species diversity of waterfowl at the monitoring plot

В 2018 г. отмечалось полное исчезновение достаточно крупной колонии черношейной поганки (Podiceps nigricolis), численность которой варьировалась в 2012-2017 гг. от 45 до 70 гнездящихся пар. Данный вид тесно взаимосвязан с озерной чайкой в период гнездования [5]. Поэтому очевидно, что исчезновение черношейной поганки происходило параллельно с деградацией колонии озерной чайки.

Негативный тренд численности отмечен также для лысухи (Fulica atra), численность которой катастрофически снизилась: с 25 пар в 2012 г. до 2 пар в 2018 г.

Зарастание водной поверхности отрицательно сказалось и на большинстве видов утиных. Так, численность наиболее массового вида этой группы - кряквы (Anas platyrchynchos) - снизилась почти в 3 раза: с 30 пар в 2012 г. до 13 пар в 2018 г. Количество гнездящихся пар красно- 
головой чернети (Aythya ferina) снизилось с 6 пар в 2012 г. до 4 пар в 2018 г. Численность хохлатой чернети (Aythya fuligula) на начальных этапах исследования достигала 10 пар, а к 2018 г. данный вид исчез с территории. Сокращение численности кряквы, хохлатой и красноголовой чернетей, видимо, явилось следствием уменьшения площади открытой водной поверхности, где предпочитают кормиться данные виды. Другие представители утиных - чирок-трескунок (Anas querquedula) и серая утка (Anas strepera) - гнездились на данной территории в 2012-2017 гг. с достаточно стабильной, хоть и невысокой, численностью: 2-4 и 1-5 пар соответственно. Однако в 2018 г. чирок-трескунок исчез с данной территории, а численность серой утки вновь снизилась до минимума.

С другой стороны, происходящие на мониторинговой площадке растительные сукцессии способствовали росту численности некоторых видов и привлекли ранее не обитавших на данной территории птиц, способствуя увеличению видового разнообразия водно-болотных птиц по крайней мере до 2016-2017 гг. В частности, численность большой поганки (Podiceps cristatus) за весь период исследований увеличилась в 2 раза - от 6 до 12 пар. В 2015 г. список обитателей обследуемой территории пополнился широконоской (Anas clypeata) и серым гусем (Anser anser), а в 2016 г. - свиязью (Anas penelope). Следует отметить, что за период исследований постоянно регистрировали пару лебедей-кликунов (Cygnus cygnus) и от 2 до 4 пар лебедя-шипуна (Cygnus olor). Примечательно, что в 2017 г., когда было обнаружено 4 пары шипуна, минимальное расстояние между соседними жилыми гнездами составляло 30 м.

В целом, на основании анализа динамики численности и видового состава водно-болотных птиц, а также биотопической структуры территории мониторингового участка было выделено три группы факторов, которые способствовали изменениям орнитофауны, - гидрологический, биотопический и фактор беспокойства.

Гидрологический фактор. Возведенные в ходе ренатурализации отработанного торфяника гидрорегулирующие сооружения были предназначены для поддержания уровня воды на относительно постоянном уровне. Однако в период наших исследований уровень воды затопленной торфоразработки значительно колебался в зависимости от климатических условий конкретного сезона, в первую очередь - от уровня и продолжительности весеннего паводка [6]. Так, в 2012 г. уровень воды держался на отметке 1-1,5 м, а глубина в каналах достигала 3 м. В период с 2015 по 2017 г. при некоторых колебаниях произошло его незначительное снижение - уровень воды держался в основном на отметке в 1 м [2], однако в каналах он оставался без изменений. Это связано с неустойчивыми гидрологическими показателями за этот период. Весенний паводок заканчивался к началу второй декады апреля, а количество осадков держалось на среднем уровне. Однако в мае 2017 г., в частности в начале мая, фиксировались ночные заморозки и количество осадков было ниже нормы, что приводило к снижению уровня воды в реках и озерах [7]. В 2018 г. тенденция продолжилась и уровень воды не превышал 1 м. Даже в каналах наблюдалось его снижение с 3 до 2 м. Такое значительное падение уровня воды по сравнению с таковым в 2012 г. стало результатом засушливых погодных условий в мае. В то же время, несмотря на то что, по данным гидрометцентра Беларуси, уровень воды в реках и водоемах в конце апреля превышал среднестатистическую норму, в последующем он значительно снизился [7].

Биотопический фактор. В результате происходящих на мониторинговой площадке гидрологических изменений увеличилась площадь межкарьерных бровок и мелководных участков, начали появляться новые участки суши (островки) и сплавины. Сказалось это и на характере распределения водной и надводной растительности, что выразилось в прогрессирующем зарастании модельного участка. В процессе сукцессионных изменений происходило увеличение территории участков надводной растительности, что влекло за собой уменьшение площади открытой водной поверхности, которая в 2012 г. составляла около 70 \% от общей площади мониторинговой площадки, а в 2018 г. - $42 \%$. Повышенное увлажнение почвы на открытых участках способствовало быстрому зарастанию территории травянистой и древесно-кустарниковой растительностью. Сукцессионные изменения сказались на численности и видовом разнообразии обитающих здесь представителей водно-болотной орнитофауны.

Фактор беспокойства - еще один важный фактор, который мог влиять на сообщество водно-болотных птиц на мониторинговой площадке. Наличие у границы территории оживленной 
трассы М6 Минск - Гродно позволило добираться сюда жителям других деревень и городов, а в результате изменения гидрорежима участка данная территория стала более посещаемой. Это повлекло за собой увеличение негативного антропогенного воздействия на гнездящихся водно-болотных птиц. Прежде всего, частое вспугивание неизбежно нарушает ритм суточной активности животного - прерывает его отдых, добывание пищи и т. п. [8]. Приближение человека заставляет насиживающую особь слетать с кладки, вызывает волнение у птиц, что может привести к хаосу, в результате которого могут быть разрушены гнезда или утоплена часть яиц. Неосторожность людей также может стать причиной разрушения гнезд и уничтожения кладок. Таким образом, фактор беспокойства мог оказать дополнительное отрицательное воздействие на большинство видов (в частности, таких, как озерная чайка, черношейная поганка, лысуха и др.), значительно снизивших численность. Так, лысуха предпочитает располагать гнезда в прибрежной полосе зарослей рогоза, тростника и камыша. У озерной чайки гибель птенцов при беспокойстве колонии может достигать серьезных масштабов в результате агрессивного поведения взрослых по отношению к чужим птенцам [9]. Кроме того, с увеличением доступности данной территории воздействие факторов беспокойства на птиц также возрастало, что в конечном итоге могло влиять как на выбор места для размножения, так и на численность вида в общем.

Заключение. Таким образом, нами выявлен ряд факторов, которые влияли на изменения в сообществе водно-болотных птиц на территории заболоченной торфоразработки. Все они оказывали комплексное воздействие, причем изменение степени влияния одного фактора могло изменять силу воздействия другого. Следует также отметить неодинаковое воздействие различных факторов на разные виды водно-болотных птиц. Так, в результате изменения гидрорежима, который способствовал растительным сукцессиям (зарастанию территории), уменьшилась численность видов птиц, нуждающихся в значительной обводненности местообитания (озерная чайка, черношейная поганка, лысуха, кряква, нырковые утки и др.). Однако при этом были созданы новые условия (кормовые, защитные), благоприятные для таких видов, таких как серый гусь, лебедь-кликун и большая поганка.

\section{Список использованных источников}

1. Отчет о реализации проекта ПРООН/ГЭФ «Ренатурализация и устойчивое управление торфяными болотами для предотвращения деградации земель, изменений климата и обеспечения сохранения глобально значимого биологического разнообразия». - Минск, 2010. - $47 \mathrm{c}$.

2. Гричик, В.В. Численность и особенности биологии массовых видов водоплавающих и околоводных птиц отработанных торфяных карьеров «Докудовское» после их повторного заболачивания / В. В. Гричик, А.С. Пышко // Зоологические чтения : сб. ст. междунар. науч.-практ. конф., посвящ. памяти проф. К.М. Ельского (Гродно, 1517 марта 2017 г.) / редкол. : О. В. Янчуревич (отв. ред.) [и др.]. - Гродно, 2017. - С. $72-73$.

3. Пышко, А.С. Видовой состав и динамика численности водно-болотных птиц на территории ренатурализированных торфяных месторождений (на примере торфоразработки «Докудовское») / А.С. Пышко, В.В. Гричик // Актуальные проблемы зоологической науки в Беларуси : материалы XI Зоол. Междунар. науч.-практ. конф. (г. Минск, 1-3 нояб. 2017 г.) : в 2 т. / редкол. : О. И. Бородин (гл. ред.) [и др.]. - Минск, 2017. - Т. 1. - С. 336-341.

4. Гричик, В.В. Гнездящиеся водоплавающие и околоводные птицы отработанных торфоразработок на ранних стадиях ренатурализации / В. В. Гричик, А. С. Пышко // Рус. орнитол. журн. - 2017. - Т. 26, № 1515. - С. 4415-4422.

5. Лямехов, Ю.Г. Биология гнездовой жизни колониальных видов птиц (на примере черношейной поганки и озерной чайки) : автореф. дис. ... канд. биол. наук : 03.00.08 / Ю. Г. Лямехов ; Перм. гос. пед. ун-т. - Пермь, 1998. - 17 с.

6. Чудненко, Д.Е. Факторы, определяющие сукцессию орнитокомплексов торфоразработок Восточного Верхневолжья / Д. Е. Чудненко // Вестн. Костром. гос. ун-та. им. Н. А. Некрасова. - 2007. - Т. 13, № 1. - С. 16-18.

7. MeteoInfo.by [Электронный ресурс]. - Режим доступа : http://meteoinfo.by/news/. - Дата доступа : 08.09.2018.

8. Юргенсон, П. Б. Роль фактора беспокойства в экологии зверей и птиц / П. Б. Юргенсон // Рус. орнитол. журн. 2013. - Т. 22, № 891. - С. 1683-1689.

9. Птицы СССР. Чайковые / В. О. Авданин [и др.] ; отв. ред. : В. Д. Ильичев, В. А. Зубакин. - М. : Наука, 1988. - 414 с.

\section{References}

1. Renaturalization and sustainable management of peat bogs to prevent land degradation, climate change and ensure conservation of globally significant biological diversity. Minsk, 2010. 47 p. (in Russian).

2. Grichik V. V., Pyshko A. S. Number and peculiarities of the biology of mass species of waterfowl and waterbirds of the dug peat pits "Dokudovskoe" after their repeated bogging. Zoologicheskie chteniya: sbornik statei mezhdunarodnoi nauchno-prakticheskoi konferentsii, posvyashchennoi pamyati professora K. M. El'skogo (Grodno, 15-17 marta 2017 goda) 
[Zoological readings: a collection of articles of the international scientific-practical conference dedicated to the memory of Professor K. M. Yelsky (Grodno, March 15-17, 2017)]. Grodno, 2017, pp. $72-73$ (in Russian).

3. Pyshko A. S., Grichik V. V. Species composition and dynamics of the number of waterbird birds in the territory of renaturalized peat deposits (for example, peat extraction «Dokudovskoe»)]. Aktual'nye problemy zoologicheskoi nauki v Belarusi: materialy XI Zoologicheskoi Mezhdunarodnoi nauchno-prakticheskoi konferentsii (Minsk, 1-3 noyabrya 2017 goda). Tom 1 [Actual problems of zoological science in Belarus: materials of the XI Zoological International scientific and practical conference (Minsk, 1-3 November 2017). Vol. 1]. Minsk, 2017. 336 p. (in Russian).

4. Grichik V. V., Pyshko A. S. Nesting waterfowl and waterbirds of spent peat extraction in the early stages of renaturalization. Russkii ornitologicheskii zhurnal [Russian ornithological journal], 2017, vol. 26, no. 1515, pp. 4415-4422 (in Russian).

5. Lyamekhov Yu. G. Biology of nesting life of colonial bird species (on the example of black-eared toadstool and black-headed gull. Abstract of Ph. D. diss. Permian, 1998. 17 p. (in Russian).

6. Chudnenko D. E. Factors determining the succession of the ornithocomplexes of peat cultivation in the Eastern Upper Volga Region]. Vestnik Kostromskogo gosudarstvennogo universiteta imeni N. A. Nekrasova [Bulletin of the Kostroma State University named after N. A. Nekrasov], 2007, vol. 13, no. 1, pp. 16-18 (in Russian).

7. MeteoInfo.by. Available at: http://meteoinfo.by/news/ (accessed 08.09.2018) (in Russian).

8. Yurgenson P. B. Role of the factor of concern in the ecology of animals and birds. Russkii ornitologicheskii zhurnal [Russian ornithological journal], 2013, vol. 22, no. 891, pp. 1683-1689 (in Russian).

9. Avdanin V. O., Avdanin V. O., Viksne Ya. A., Zubakin V. A., Kishchinskii A. A., Litvinenko N. M. [et al.]. Birds of the USSR. Seagulls. Moscow, Nauka Publ., 1988. 414 p. (in Russian).

\section{Информация об авторе}

Пьико Александр Сергеевич - мл. науч. сотрудник. Научно-практический центр НАН Беларуси по биоресурсам (ул. Академическая, 27, 220072, г. Минск, Республика Беларусь). E-mail: aleksandr.ph95@gmail.com

\section{Information about the author}

Alexander S. Pyshko - Junior researcher. Scientific and Practical Center for Bioresources of the National Academy of Sciences of Belarus (27, Akademicheskaya Str., 220072, Minsk, Republic of Belarus). E-mail: aleksandr.ph95@, gmail.com 